\title{
JUURNAL_RU
}

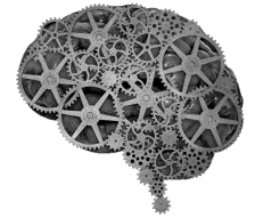

COMPANY GROUP "INTELLEKT"

\author{
Шитов А.М., Кондратьев И.М., Орлов А.В. \\ Институт машиноведения им. А.А. Благонравова РАН \\ Москва, Россия
}

doi: 10.18411//j2016-9-2-13

idsp 000001: lj2016-18-2-13

\section{Система регистрации и обработки диагностических параметров узлов металлорежущих станков}

В Институте машиноведения РАН разработаны методики диагностирования различных узлов металлорежущих станков. При этом разработанные методики базируются на системном подходе и реализованы в виде систем регистрации и обработки диагностических параметров, представляющих собой программно-аппаратные комплексы (ПАК), с помощью которых измеряются наиболее информативно значимые параметры (жесткостные, температурные, вибрационные, точностные и др.) [1] и по совокупности их значений устанавливается диагноз о состоянии станка.

В качестве примера рассмотрим реализацию ПАК для шпиндельного узла (ШУ) - одного из важнейших компонентов станка ([2], [3], [4]). Аппаратная часть ПАК для диагностики шпиндельного узла представлена набором датчиков и вторичных блоков преобразователей, подключенных к компьютеру (рис.1). Особенностью аппаратной части является возможность использования различных видов формирования выходного сигнала - от аналоговых постоянного и переменного тока до интеллектуальных цифровых с USBинтерфейсом. Датчики предназначены для регистрации таких диагностических параметров шпиндельного узла как биение оси, вибрация, температура подшипниковых опор, угловая скорость и нагрузочные усилия.

С помощью программной части комплекса выполняются две основные функции - сбор данных с датчиков и формирование диагноза о состоянии шпиндельного узла. Кроме того, она обеспечивает выполнение необходимых 
промежуточных вычислений. Все компоненты программной части объединены единым графическим интерфейсом, обеспечивающим удобство ввода исходных данных и наглядность представления получаемых результатов. Основным результатом работы программ является протокол о состоянии ШУ, являющийся документом, на основании которого принимают управленческие решения.

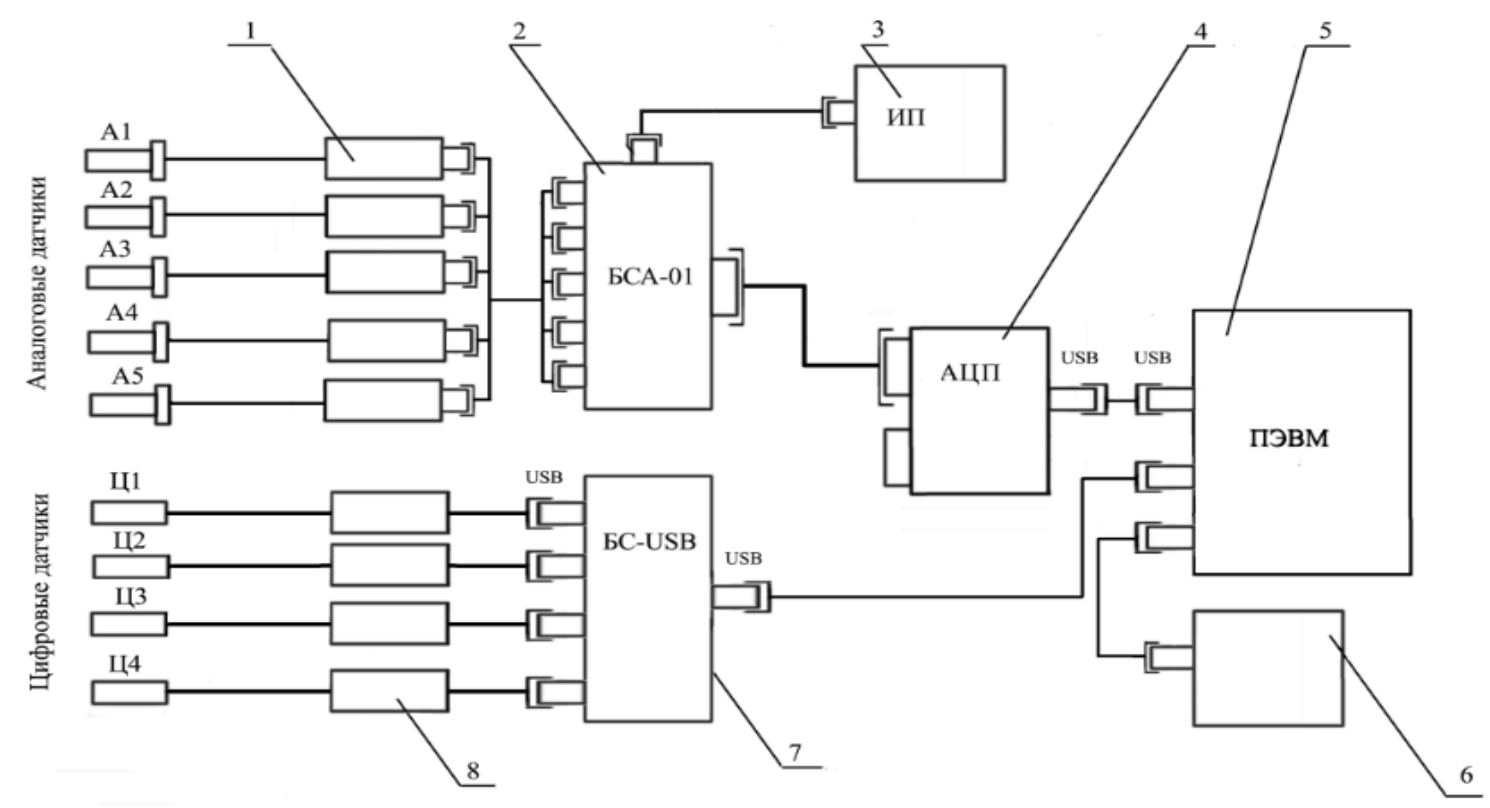

Рисунок

1 - Блок-схема аппаратной части комплекса: 1 - плата элементов схемы аналогового датчика; 2 - блок питания аналоговых датчиков; 3 - источник питания; 4 - аналого-цифровой преобразователь; 5 - персональный компьютер; 6 - принтер; 7 - конвертор USB; 8 - электронные блоки цифровых датчиков.

ПАК шпиндельного узла позволяет выполнять диагностирование по нескольким основным параметрам: геометрическим, податливости/жесткости, биению оси вращения, вибрации, температуре, энергетическим потерям и собственным частотам. Часть из этих параметров (к этой группе относится, например, температура) контролируется непосредственно, а другая определяется после дополнительной обработки информации и расчетов (в частности, жесткостные параметры и так называемые подшипниковые частоты).

Так, для оценки ШУ по параметрам радиальной и осевой податливости рассматриваются различные конструктивные схемы, с помощью математических моделей определяются нормы податливости и предельные значения.

Для диагноза по параметру вибрация разработана программа, позволяющая рассчитывать диагностические подшипниковые частоты, определять предельные уровни вибрации по каждой из диагностических частот, 
рассчитывать среднее квадратическое значение виброскорости и пик-фактор. С помощью частотного анализа измеренного вибрационного сигнала оценивается наличие и степень проявления различных дефектов подшипников, а также прогнозируется их развитие при дальнейшей эксплуатации шпиндельного узла.

При проведении диагноза по параметру биение оси шпинделя используются показания датчиков малых перемещений и угла поворота оси шпинделя, после чего строятся круглограммы, характеризующие точность формообразования при заданной частоте вращения и температуре подшипников.

При оценке состояния ШУ по температуре подшипников исходной информацией являются показания датчиков температуры, расположенных в зоне подшипниковых опор. Измеренная температура сравнивается с предельно допустимыми уровнями температуры; кроме того контролируется скорость повышения температуры.

При диагностировании состояния ШУ по параметру трения в подшипниках, т.е. энергетических потерь при вращении шпинделя, используются показания с датчиков тока и угловой скорости.

Для оценки по параметру виброустойчивости рассчитываются главные собственные частоты для различных конструктивных схем и с учетом коэффициентов податливости системы СПИД (станок-приспособлениеинструмент-деталь) и демпфирования определяются допустимый режим обработки и степень устойчивости станка при резании. При этом для определения собственных частот ШУ и расчета коэффициентов демпфирования используются данные с датчика силы (тензометрический молоток) и бесконтактного датчика малых перемещений. По полученным экспериментально значениям рассчитывается критерий устойчивости (Найквиста) и определяется предельная ширина стружки, которая сравнивается с предельным значением ширины стружки, полученным при резании на заданных режимах обработки.

Диагнозы, полученные от всех программ комплекса, сводятся в единый протокол, являющийся главным документом о проверке состояния ШУ.

Кроме того, ПАК позволяет хранить и накапливать информацию о проведенных проверках ШУ, которая затем используется для планирования последующих проверок и расчета остаточного ресурса ШУ. 
Комплекс для диагностирования шпиндельных узлов работает в составе специализированного испытательного стенда, оснащенного нагрузочными устройствами для имитации реальных нагрузок и позволяющего осуществлять резание на заданных режимах с реальными наладками станка.

\section{Литература:}

1. Конструирование машин. Том 2 //Справочно-методическое пособие в 2-х т. - М.: Машиностроение, 1994.

2. Комплексная методика диагностирования шпиндельных узлов станков /Шитов А.М., Алешин А.К., Кондратьев И.М., Щусев Д.В. //В сборнике: Научные труды IV Международной научной конференции “Фундаментальные исследования и инновационные технологии в машиностроении". - 2015. - С. 271-273.

3. Кондратьев И.М., Орлов А.В., Шитов А.М. Система сбора данных для оперативной вибродиагностики шпиндельных узлов //Проблемы машиностроения и автоматизации. - 2013. - № 2. - С. 62-67.

4. Шитов А.М., Кондратьев И.М., Орлов А.В. Аппаратно-программный комплекс для диагностики шпиндельных узлов станков //Сборник научных трудов XIII международной научной конференции «Тенденции развития науки и образования». Часть 3. - 2016. - С.34-35. 